\title{
Construção da relação entre confiança e as cinco disciplinas de Senge na gestão de equipes virtuais e semi- virtuais
}

\author{
Marina Keiko Nakayama, Dra. - UFSC - marina@egc.ufsc.br \\ Andressa Sasaki Vasques Pacheco, Msc. - UFSC - andressa@ead.ufsc.br \\ Kelly Cristina Benetti, Adm. - UFSC - kellyadm@ hotmail.com \\ Alexandre Marino Costa, Dr. - UFSC - marino@cse.ufsc.br \\ Eleonora Vieira Falcão, Dra. - UFSC - eleonorafalcao@gmail.com \\ Bianca Smith Pila - bspila@gmail.com
}

\begin{abstract}
Resumo
Este artigo relata uma pesquisa realizada com uma equipe semivirtual de tutores no curso de Administração a distância da Universidade Federal de Santa Catarina - UFSC cujo objetivo foi o de analisar a relação entre a presença da confiança e das cinco disciplinas propostas por Senge nas equipes virtuais ou equipes semi-virtuais considerando o caso da equipe da tutoria do referido curso. O referencial teórico utilizado fundamenta-se no conceito de confiança organizacional e nas cinco disciplinas de Senge. O método utilizado foi o estudo de caso descritivo empregando análise documental, questionário e observação participante. Verificou-se nos resultados que a confiança predomina nas relações da equipe pesquisada. O resultado pode-se ser explicado pela percepção por parte dos participantes sobre o bom nível de competência da equipe, sobre a existência do compartilhamento e sobre a combinação positiva de sentimentos, interesses, opiniões, propósitos e valores entre os membros. Pode-se perceber a aderência das disciplinas de Senge com a equipe pesquisada. Ressalta-se que a equipe pesquisada foi gerenciada, anteriormente, ao longo de sete meses de forma a promover melhorias na comunicação o que pode fazer a diferença nos resultados encontrados.
\end{abstract}

Palavras-chave: equipes, confiança, educação a distância, disciplinas de Senge

\section{The construccion of a relationship between confidence and the Senge's five disciplines in the virtual and semivirtual teams management}

\begin{abstract}
This article tells a research carried through with a semivirtual team of tutors in the course of Administration of the UFSC by distance whose objective was to analyze the relation between the presence of the confidence and of the five discipline proposed by Senge in the semivirtual and virtual teams considering the case of the team of the guardianship of the referred course. The used theoretical referencial is based on the organizacional confidence concept and in the five disciplines of Senge. The used method was the descriptive study of case using documentary analysis, questionnaire and participant comment. It was verified in the results that the confidence predominates in the relations of the searched team. The result can be explained by the perception of part of the participants on the good level of ability of the team, on the existence of the sharing and the positive combination of feelings, interests, opinions, intentions and values between the members. The tack can be perceived of Senge's disciplines with the searched team. It is standed out that the searched team was managed, previously, throughout seven months of form to promote improvements in the communication what it can make the difference in the joined results.

Key-words: team, confidence, distance education, Senge's disciplinies.
\end{abstract}




\section{INTRODUÇÃO}

A atual evolução do mundo está diretamente ligada ao aprendizado e desenvolvimento das novas tecnologias, notadamente aquelas que se referem ao intercâmbio de informações. Agilidade, eficiência e precisão são requisitos importantes nos processos; o manejo de informações por meios virtuais via Internet, áudio/vídeo/teleconferências, entre outros tem fornecido um suporte fundamental a essa demanda. Por essas razões, o trabalho de equipes virtuais e semi virtuais vem salientando-se em importância, e é objeto de estudo em diversas áreas do conhecimento.

A confiança nas organizações opera simultaneamente em diversos níveis entre a alta administração, líderes, equipes de trabalho, colaboradores, parcerias comerciais, etc. e um desses níveis remete às equipes virtuais.

Muitos pesquisadores já reconheceram que confiança representa uma variável crítica influenciando o desempenho, eficácia e eficiência das organizações (MAYER; DAVIS, 1999; KRAMER; TYLER, 1996; WHITNEY, 1994; MAYER; DAVIS; SCHOORMAN, 1995; LEWICKI; MCALLISTER; BIES, 1998).Grande quantidade da pesquisa literária foca os modos de desenvolver e realçar confiança entre os empregados (GAMBETTA, 1988), sugerindo que organizações considerem confiança como um atributo desejável. Apoio para essa perspectiva é mostrado por estudos que ligam confiança com uma variedade de comportamentos de trabalho, incluindo comportamento de cidadania organizacional (KONOVSKY; PUGH, 1994), desempenho do empregado (MAYER; DAVIS, 1999), solução de problema (ZAND, 1972), apoio para autoridades (BROCKNER; SIEGEL; DALY; TYLER; MARTIN, 1997), acordo de ganhos mútuos (FRIEDMAN, 1993) e compromisso organizacional (COOK; WALL, 1980). Conforme pode-se verificar na pesquisa sobre a confiança como indicador de desempenho em equipes virtuais em Nakayama, Binotto e Pilla, 2006.

Portanto, é importante compreender que a confiança entre os membros de uma equipe facilita a aprendizagem dentro e fora da equipe. Esse relacionamento influencia diretamente na aplicação das cinco disciplinas de Senge (1998) que são domínio pessoal, modelos mentais, objetivo comum, aprendizado em grupo e visão sistêmica.

Baseados nesse pressuposto da significativa relação entre confiança, as cinco disciplinas e bom desempenho de equipe virtual ou semi-virtual elaborou-se a questão da pesquisa: Qual é a relação entre a presença da confiança e das cinco disciplinas propostas por Senge nas equipes virtuais ou equipes semi-virtuais?

Para tanto os objetivo geral da pesquisa é analisar a relação entre a presença da confiança e das cinco disciplinas propostas por Senge nas equipes virtuais ou equipes semi-virtuais considerando o caso da equipe da tutoria do curso de graduação em administração na modalidade a distância da Universidade Federal de Santa Catarina UFSC.

E os objetivos específicos são:

a) verificar como as pessoas percebem a confiança entre os membros de equipes virtuais e semi-virtuais;

b) examinar como os membros das equipes virtuais ou semi-virtuais percebem a presença de cada uma das cinco disciplinas de Senge; e

c) identificar qual a relação entre a percepção da presença ou não da confiança e das cinco disciplinas. Desta forma, foi eleito como caso de estudo a equipe de tutores do curso de graduação em administração na modalidade a distância da UFSC devido à sua classificação como equipe semi-virtual.

\section{FUNDAMENTAÇÃO TEÓRICA}




\subsection{Confiança}

Definições prévias sobre a confiança implicam em três conceitos-base: (1) vulnerabilidade (CURRALL; JUDGE, 1995), (2) reciprocidade (ZAND, 1972) e (3) expectativa (LEWICKI; BUNKER, 1996). Dessa pesquisa, definimos confiança nesse estudo como uma disposição de aumentar vulnerabilidade em outra equipe, baseada em expectativa positiva, resultante de positivas interações mútuas passadas. Essa definição de confiança reflete os três conceitos-base de confiança, bem como o âmbito dinâmico do ciclo de confiança. Ser vulnerável significa a possibilidade de ser prejudicado e vivenciar potencialmente resultados negativos.

Por exemplo, a compreendida probabilidade de perda, quando interpretada por um tomador-de-decisão, é um fator-chave no comportamento de confiança (CHILES; MCMACKIN, 1996). Isso enfatiza um incontestável conhecimento histórico, o qual eleva expectativas positivas sobre outra equipe. Além disso, um forte conjunto de livros especializados tem enfatizado a importância da interação positiva entre equipes, o que aumenta o nível de confiança (ZAND, 1972; BUTLER, 1983). Uma revisão de várias definições de confiança é resumida no quadro 1.

\begin{tabular}{|c|c|}
\hline Autores & Definição \\
\hline Griffin. 1967 & $\begin{array}{l}\text { A confiança sobre as características de um objeto, ou a ocorrência de um evento, } \\
\text { ou o comportamento de uma pessoa a fim de obter um desejado, mas incerto } \\
\text { objetivo em uma situação de risco. }\end{array}$ \\
\hline Roter, 1967 & $\begin{array}{l}\text { Uma expectativa mantida por um indivíduo ou grupo que a palavra, promessa, } \\
\text { declaração verbal ou escrita de outro indivíduo ou grupo possa ser confiada. }\end{array}$ \\
\hline Driscoll, 1978 & $\begin{array}{l}\text { A convicção que os tomadores-de-decisão irão produzir resultados favoráveis aos } \\
\text { interesses da pessoa sem nenhuma influência dessa pessoa. }\end{array}$ \\
\hline $\begin{array}{l}\text { Frost, Stimpson \& } \\
\text { Maughan, } 1978\end{array}$ & $\begin{array}{l}\text { Uma expectativa mantida por um indivíduo que o comportamento (verbal ou não } \\
\text { verbal) de outro indivíduo ou grupo de indivíduos seja altruísta e pessoalmente } \\
\text { benéfica para ele mesmo. }\end{array}$ \\
\hline $\begin{array}{l}\text { Larzelere \& Huston, } \\
\qquad 1980\end{array}$ & $\begin{array}{l}\text { O grau (PONTO) que uma pessoa acredita outra pessoa (ou pessoas) ser } \\
\text { benevolente e honesta. }\end{array}$ \\
\hline $\begin{array}{l}\text { Lewis \& Weigert, } \\
1985\end{array}$ & $\begin{array}{l}\text { A realização (GARANTIA) de um arriscado curso de ação na expectativa } \\
\text { confiante que todas as pessoas envolvidas na ação vão agir competentemente e } \\
\text { obedientemente. }\end{array}$ \\
\hline Zucker, 1986 & $\begin{array}{l}\text { Um conjunto de expectativas dividido por todos aqueles envolvidos em uma } \\
\text { troca. }\end{array}$ \\
\hline $\begin{array}{l}\text { Bradach \& Eccles, } \\
1989\end{array}$ & $\begin{array}{l}\text { Um tipo de expectativa que alivia o medo que o parceiro de troca de alguém irá } \\
\text { agir de forma oportunista. }\end{array}$ \\
\hline Fukuyama, 1995 & $\begin{array}{l}\text { As expectativas que surgem dentro de uma comunidade de comportamento } \\
\text { regular, honesto e cooperativo, baseado em normas divididas comumente da } \\
\text { função de outros membros daquela comunidade. }\end{array}$ \\
\hline $\begin{array}{l}\text { Currall \& Judge, } \\
1995\end{array}$ & $\begin{array}{l}\text { Confiança comportamental do indivíduo em outra pessoa sob uma condição de } \\
\text { risco. }\end{array}$ \\
\hline Robinson, 1996 & $\begin{array}{l}\text { Como as expectativas, crenças ou suposição de alguém sobre a probabilidade que } \\
\text { futuras ações de outro serão benéficas, favoráveis ou pelo menos não nociva aos } \\
\text { interesses de alguém. }\end{array}$ \\
\hline $\begin{array}{l}\text { Doney \& Cannon, } \\
1997\end{array}$ & Credibilidade compreendida e benevolência de um alvo de confiança \\
\hline $\begin{array}{l}\text { Clark \& Payne, } \\
1997\end{array}$ & $\begin{array}{l}\text { Um estado de espírito daqueles que confiam em relação a aqueles que receberam a } \\
\text { confiança. }\end{array}$ \\
\hline
\end{tabular}

Quadro 1: Conceitos de confiança

Fonte: Adaptado de Tzafir e Harel (2002)

\subsection{A quinta disciplina}


A teoria de Senge (1998) trata da apresentação dos requisitos para a transformação em uma organização que aprende. Para isso são abordadas cinco disciplinas principais: domínio pessoal, modelos mentais, visão compartilhada, aprendizagem em grupo e pensamento sistêmico (a quinta disciplina). Apresenta-se a seguir a explanação sobre essas disciplinas, enfocando primeiramente os relativos sobre o indivíduo, passando-se ao grupo e ao organizacional.

Inicia-se, portanto, com a discussão sobre o domínio pessoal, sendo este já tratado por outros autores, mas essencial etapa para a formação da aprendizagem da organização. De acordo com Senge (1998) o verdadeiro crescimento espiritual nos expõe a uma realidade mais profunda; ensina-nos a ver a realidade atual com mais clareza e, ao ressaltar a diferença entre visão e realidade atual, gera tensão criativa da qual resulta a aprendizagem eficaz.

Complementa-se ainda que uma organização que aprende é "um grupo de pessoas que aperfeiçoam continuamente a capacidade de criar o seu futuro, mudando o ser humano para que produza resultados que lhe interessam e realiza coisas que lhe são importantes".

A busca pelo domínio pessoal leva a certeza da "ignorância", ou seja, quanto mais se estuda e agrega conhecimento, mais é reconhecido o quão pouco se conhece do mundo.

O conceito de domínio pessoal pode ser complementado com o conceito de uma pessoa empreendedora, a qual está "aberta" a percepções de novas oportunidades e conhecimentos, colocando-os em prática.

Resgatando-se o conceito de competências, como sendo conhecimentos, habilidades e atitudes, faz-se um paralelo com o domínio pessoal, o qual deve ser receptivo a aprendizagem de competências, um novo saber, ser e fazer.

A próxima disciplina a ser abordada são os modelos mentais: a abordagem sistemática continua com a ênfase dada por Senge aos modelos mentais. Essa disciplina exige que os gestores construam modelos mentais para as forças propulsoras que estão por trás dos valores e princípios da organização. Senge alerta seus leitores para o impacto, na esfera organizacional, de modelos mentais adquiridos, e para a necessidade de criar mecanismos indefensáveis para examinar sua natureza.

Quanto aos modelos mentais, pode-se relacioná-los também com cultura e valores. Como são desenvolvidos ao longo do tempo, são difíceis de serem mudados, sendo necessária uma pré-disposição, ou seja, uma abertura a essa nova aprendizagem.

Esses modelos são observados tanto nas esferas individuais quanto nas organizacionais. Como exemplo, pode-se citar os estudantes a distância. Muitos estão arraigados à metodologia do ensino presencial, fazendo com que haja resistência com as metodologias dessa nova modalidade, ocasionando a não adaptação e em conseqüência sua evasão do curso. Percebe-se tanto a presença de um modelo mental "fechado" como um domínio pessoal não desenvolvido para novas experiências.

Passando-se a uma transição entre o individual e o coletivo, apresenta-se a visão compartilhada: segundo Senge, a verdadeira criatividade e inovação são baseadas na criatividade do grupo e a visão pessoal de seus membros. A visão compartilhada ocorre quando a visão não é mais vista como separada do eu.

Quanto à visão compartilhada, encontra-se um paradoxo, sendo que se apresenta a idéia da busca por equipes heterogêneas, sendo que este fato pode levar a uma maior dificuldade de integração entre os objetivos organizacionais e pessoais.

A participação e o comprometimento são palavras chaves no processo de compartilhamento da visão, pois é necessário o sentimento de pertença, ou seja, sentir fazer parte do todo, bem como o comprometimento remete à busca de objetivos conciliatórios e paralelos. 
Ainda em relação ao coletivo, tem-se a aprendizagem em grupo: a aprendizagem eficaz em grupo envolve processos alternativos de dialogo e discussão. O diálogo é exploratório e amplia as possibilidades, enquanto a discussão reduz as opções de encontrar as melhores alternativas para decisões futuras. Embora esses dois processos sejam complementares, precisam ser separados. Infelizmente, muitos grupos são desprovidos da capacidade de distinguir entre os dois e de saber passar um para outro.

Além disso, a aprendizagem em grupo apresenta um conceito de sinergia, ou seja, a soma das partes é maior que o todo. A troca de idéias, reflexos e todo o diálogo envolvidos nessa disciplina são necessários para que o resultado alcançado tenha reflexos desde o nível individual ao organizacional.

Finalmente agregam-se as reflexões sobre pensamento sistêmico, fonte integradora das outras abordagens e essencial para a construção da aprendizagem em uma organização: a abordagem organizacional. Pode-se considerar a organização como um ente vivo, com comportamento e padrões de aprendizagem próprios.

Apresenta-se também a idéia de "arquétipos sistêmicos" para auxiliar gerentes a reconhecer padrões repetitivos, os quais podem levar a problemas recorrentes ou limitar o crescimento.

A premissa básica de Senge é: as pessoas devem deixar de lado suas antigas formas de pensar (modelos mentais); aprender a ser receptivas com os demais (domínio pessoal); entender como a empresa funciona (pensamento sistêmico; fazer um plano que conte com a concordância de todos uma visão compartilhada); e depois trabalhar juntas para alcançar essa visão (aprendizagem em grupo).

A principal crítica que pode ser feita ao trabalho de Senge é a dificuldade inerente de aplica seus modelos. Senge formou-se em engenharia e depois se envolveu em pesquisa social. Ambas exigem abordagem sistemática, que não pode ser desenvolvida com facilidade. Na verdade, o pensamento sistêmico é tão fácil como aprender neurocirurgia em curso de três dias. Nem a maioria das empresas pode se dar ao luxo de ter seus altos executivos "dando cabeçadas" para entender, durante muito tempo.

Quebrar velhos hábitos empresariais é muito difícil. Portanto, transformar uma empresa em uma organização que aprende é muito problemático e não é para os covardes. A razão disso é muito simples, para avançar para um modelo novo e coletivo de aprendizagem, os gestores têm de renunciar às suas áreas tradicionais de poder e controle. Têm de entregar o poder para os aprendizes e permitir q cometam erros. Em uma cultura baseada na culpa, uma mudança de atitude como essa continua sendo um grande obstáculo.

Apesar da intangibilidade de seus ideais, A Quinta Disciplina foi extremamente influente. Seus conceitos estimularam o debate e a aceitação de questões como o desenvolvimento autogerido, empowement e criatividade. Seu efeito prático pode ser notado em estratégias modernas de gestão de recursos humanos, princípios de trabalho em grupo e em modelos de qualidade.

Talvez seja mais importante reconhecer que, na vida, todas as verdades mais profundas são ilusoriamente simples, embora quase impossíveis de aplicar na prática. A dificuldade encontrada na aplicação das idéias de Senge não as invalida - ao contrário, confirma sua importância para as empresas no século XXI (GOLEMAN, 2007).

\section{PROCEDIMENTOS METODOLÓGICOS}

Quanto ao tipo de estudo, caracteriza-se como descritiva, documental, bibliográfica, teórico-empírica, estudo de caso. Em relação à abordagem classifica-se como predominante qualitativa. 
Nesta pesquisa foram coletadas informações do curso a distância em documentos institucionais do Departamento de Ciências da Administração da Universidade Federal de Santa Catarina.

Quanto ao tipo de corte, esta pesquisa é transversal ou cross-sectional, neste caso, com os tutores participantes do segundo semestre de 2007.

Os dados primários foram coletados junto aos tutores do curso. Foram aplicados questionários 12 questionários, composto de questões abertas e fechadas com escala de avaliação verbal. Cada questão correspondia a uma das variáveis em estudo, conforme o quadro a seguir:

\begin{tabular}{|c|c|}
\hline Questão & Variável \\
\hline 1 & Domínio pessoal \\
\hline 2 & Modelos mentais \\
\hline 3 & Visão compartilhada \\
\hline 4 & Pensamento sistêmico \\
\hline 5 & Visão compartilhada \\
\hline $6-10$ & Confiança \\
\hline $11-18$ & Aprendizagem em grupo \\
\hline
\end{tabular}

Quadro 2: variáveis em estudo e questões

Fonte: dados primários

As lideranças das equipes são co-autores do presente artigo o que implica em dados de observação participante.

Após a coleta de dados vem a seção de tratamento. Os dados das questões fechadas obtidos foram tratados estatisticamente por meio da análise descritiva, com a exposição de medidas como freqüência e média. Optou-se pela utilização da unidade descritiva média para a comparação entre os termos. Destaca-se que esta média tem como valor mínimo zero e valor máximo quatro, sendo quanto maior o valor, maior a será a aprendizagem em equipe.

Outra estratégias de análise adotada foram: descritiva e interpretativa. Apesar de não ser cientificamente suficiente, é uma importante estratégia de análise já que auxilia o pesquisador a entender seu objeto de pesquisa. Devido a essa deficiência, complementou-se também com a análise de discurso.

\section{CURSO ADMINISTRAÇÃO A DISTÂNCIA DA UFSC}

Diante da demanda motivada pelo Ministério de Educação, com a finalidade de atender às necessidades das empresas estatais em termos de qualificação dos seus servidores públicos, a UFSC, em parceria com instituições de ensino superior, participa do projeto de criação do Curso de Graduação em Administração, na modalidade a distância, como um programa da Universidade Aberta do Brasil - UAB/MEC.

$O$ curso de Administração a distância da UFSC tem como objetivo geral preparar o aluno para ser um profissional criativo, com capacidade empreendedora, capaz de se integrar facilmente aos objetivos de uma organização e coordenar, em qualquer ramo de atividade, as mais importantes estratégias operacionais.

A carga horária total do curso é de 3000 (três mil) horas/aulas, sendo a maior parte ministrada a distância e não mais que $20 \%$ presencial. As presenciais constituem encontros presenciais, seminários temáticos e exames.

O currículo do Curso de Graduação em Administração na modalidade a distância tem como pressuposto a concepção de educação contínua e permanente, que possa ser oferecida pelas instituições educativas de forma aberta, sem restrições, exclusões ou privilégios. 
O curso conta com a seguinte equipe de apoio: 3 Tutores Supervisores, 14 Tutores, 1 Coordenador do Curso e 1 Coordenador da tutoria, além de uma Comissão Coordenadora (7 professores) e o Conselho Editorial (4 professores).

Destaca-se a função dos tutores os quais são facilitadores da aprendizagem, motivando e estimulando os estudantes a realizarem as atividades, esclarecendo dúvidas, reforçando a aprendizagem e também coletando informações sobre os estudantes (desempenho, notas, atividades realizadas, opiniões e sugestões). São eles os responsáveis pelo envio, recebimento e correção de atividades ao seu grupo de estudantes, para tanto, vale ressaltar que cada tutor é responsável por um grupo de 35 alunos.

\section{DESCRIÇÃO DOS RESULTADOS}

\subsection{Confiança}

Analisando os resultados em relação à confiança, percebe-se que esse é um sentimento que predomina nas relações da equipe. Essa constatação deriva de que nove dos doze respondentes afirmam que há confiança entre os membros da equipe e que isso funciona de forma positiva, e os outros três afirmam que a confiança é parcial, ou seja, depende dos interesses individuais, mas que ela existe em grande parte das situações.

Considerando a teoria que afirma que um alto nível de competência contribui para a presença da confiança na equipe, nota-se que sete membros responderam que sua equipe apresenta um bom nível de competência enquanto outros cinco destacam que o nível é aceitável, mas apresenta pontos a melhorar. Isso significa que este não é o fator preponderante para a presença da confiança nesta equipe.

Já quanto ao compartilhamento da informação, outro influenciador da confiança, é possível perceber que há maior relação, uma vez que nove membros responderam que ele acontece sempre ao passo que três destacaram que deveria ser mais intenso e aprimorado entre os turnos da manhã e da tarde.

Uma das definições de confiança é que essa significa uma combinação positiva de sentimentos, interesses, opiniões, propósitos e valores entre os membros de uma equipe. Nove pessoas responderam que há essa combinação, enquanto um deles respondeu que essa combinação é parcial, porém "a combinação parece ser positiva, no entanto é muito difícil moldar interesses, opiniões e propósitos dentro de uma equipe instável como a nossa (acadêmicos com comportamentos e objetivos muito diferentes entre si que estão aqui de forma passageira)". A colocação do respondente é interessante, uma vez que observa a situação de uma perspectiva diferente da maioria.

Na mesma linha, onze dos respondentes classificam a relação entre os membros da equipe como altruísta, enquanto um afirma que "depende de cada indivíduo, da mesma forma que encontramos pessoas totalmente dispostas e engajadas a ajudar o próximo, também há aqueles que preferem se limitar ao "seu trabalho"”.

\subsection{As cinco disciplinas}

No que tange ao domínio pessoal, seis dos membros da equipe consideram que seu trabalho proporcionou um reforço das disciplinas cursadas na graduação, cinco responderam que o trabalho contribuiu para o incremento da interação entre as pessoas e para o desenvolvimento da paciência. No mesmo sentido, quatro responderam que desenvolveram a habilidade de comunicação, e três a autoconfiança. Também foram mencionadas: objetividade, didática, trabalho em equipe, planejamento do tempo, concentração, capacidade de estabelecer objetivos, empatia e visão do todo. 
Com relação aos modelos mentais, cinco respondentes mencionaram que o trabalho ampliou sua capacidade e seu entendimento quanto ao relacionamento interpessoal. Um dos respondentes complementa essa afirmação quando expõe:

E o interessante é o compartilhamento de informações. Mesmo lendo sobre o mesmo assunto, confrontar diversos pontos de vista, debater constrói e fortalece as idéias. Quando conversamos mais sobre o assunto, além de aumentar os pontos de vista pelos quais podemos abordá-lo, fixamos melhor o conteúdo.

Outros três citaram que houve mudança significativa no seu modo de estudar. Cabe destacar o seguinte depoimento:

Acredito que o fato mais marcante foi saber que é possível gostar de um trabalho o suficiente pra ficar motivado boa parte do tempo e criar expectativas com relação ao futuro (as próximas disciplinas). Eu ainda via o trabalho como uma mera necessidade, hoje vejo como um hobby. A tutoria ajudou muito nisso, já que estudar pra mim é um hobby (com exceção de algumas matérias).

Foram citados também o espírito colaborativo, o trabalho em equipe, o processo de tomada de decisão, o processo de construção do conhecimento, saber ouvir, o equilíbrio de interesses, a mudança de perspectiva quanto ao processo de ensinoaprendizagem (de aluno a professor), o modo de ver o trabalho, a capacidade crítica e a visão holística.

Quanto à visão compartilhada, percebe-se que há um forte compartilhamento do entendimento dos objetivos do trabalho do tutor, uma vez que houve a convergência das respostas para o objetivo de auxiliar o aluno no desenvolvimento de suas atividades no curso. Uns definem de forma mais ampla, outros de forma mais objetiva. Todos projetam esse objetivo para suas equipes de forma similar e ainda percebem sua participação no alcance do objetivo do curso, que é, segundo eles, formar profissionais para o mercado de trabalho.

É importante destacar um depoimento que bem ilustra essa convergência:

O objetivo de meu trabalho está no auxilio aos alunos no sentido de facilitadora de seu aprendizado. No entanto, acredito que tal fato só pode ser conseguido através iniciativa de todos da equipe, no sentido de que os membros devem auxiliar uns aos outros facilitando o trabalho individual, somando esforços.

Assim, também se constata que o trabalho individual depende do funcionamento da equipe, uma vez que dez respondentes afirmam que se o trabalho não fosse feito em equipe impediria o compartilhamento do conhecimento. Outros cinco responderam que não seria possível a padronização do atendimento prestado, prejudicando os alunos, assim como a qualidade (duas respostas) e a eficiência (uma resposta). 
Tabela 1: Média de aprendizagem em equipe

\begin{tabular}{l|c}
\hline \multicolumn{1}{c|}{ Questão } & Média \\
\hline $\begin{array}{l}\text { O curso de administração a distância da UFSC “aprende com a experiência” e não repete os } \\
\text { erros. }\end{array}$ & 2,82 \\
\hline $\begin{array}{l}\text { Quando algum membro da equipe sai do curso de administração a distância da UFSC, seu } \\
\text { conhecimento permanece. }\end{array}$ & 2,67 \\
\hline Quando conclui uma tarefa, a equipe dissemina e documenta o que aprendeu. & 2,27 \\
\hline $\begin{array}{l}\text { O conhecimento gerado em todas as áreas do curso de administração a distância da UFSC é } \\
\text { investigado, legitimado e disponibilizado para toda a organização por meio de bancos de dados, } \\
\text { treinamento e outros eventos de aprendizagem. }\end{array}$ & 2,11 \\
\hline $\begin{array}{l}\text { O curso de administração a distância da UFSC reconhece e recompensa o valor do } \\
\text { conhecimento criado e compartilhado por pessoas e equipes. }\end{array}$ & 2,45 \\
\hline $\begin{array}{l}\text { O curso de administração a distância da UFSC avalia sistematicamente suas necessidades } \\
\text { futuras de conhecimento e desenvolve planos para atendê-las. }\end{array}$ & 2,80 \\
\hline $\begin{array}{l}\text { O curso de administração a distância da UFSC facilita a experimentação como um modo de } \\
\text { aprender. }\end{array}$ & 2,82 \\
\hline $\begin{array}{l}\text { O curso de administração a distância da UFSC aprimora suas capacidades de gerar, adquirir e } \\
\text { aplicar o conhecimento aprendendo com os processos de aprendizado de outras organizações. }\end{array}$ & 2,55 \\
\hline
\end{tabular}

Fonte: dados primários

Quanto a aprendizagem, como já descrito na metodologia deste artigo, optou-se pela utilização da unidade descritiva média para a comparação entre os termos. Destacase que esta média tem como valor mínimo zero e valor máximo quatro, sendo quanto maior o valor, maior a será a aprendizagem em equipe.

Com isso, pode-se contatar que todas as perguntas sobre aprendizagem apresentam índices positivos, ou seja, com atitudes freqüentes que facilitam a aprendizagem em equipe. No entanto, cabe destacar que os valores podem ser melhorados, pois nenhum índice alcançou valores maiores do que a pontuação 2,82 , um índice satisfatório, mas não expressivo.

Por fim, apresenta-se a quinta disciplina, o pensamento sistêmico. Constata-se que todos percebem que seu trabalho impacta no alcance dos objetivos da organização, atuando principalmente como facilitadores da aprendizagem (sete respostas), e também como suporte para os alunos (três respostas), como motivador (três respostas) e ainda como canal de comunicação (uma resposta). Conforme a declaração:

De maneira bastante profissional, contribuo com o meu conhecimento, ou quando demonstro desconhecimento, pesquiso para sanar minhas dúvidas, de modo a orientar com mais precisão aos alunos, incentivando o desenvolvimento de raciocínio crítico e analítico. Apontando para eles caminhos a serem seguidos e fazendo com que essas "trilhas" sirvam de suporte para o seu desenvolvimento profissional e pessoal.

\section{CONSIDERAÇÕES FINAIS}

Apresentando as considerações finais, destaca-se que todas as disciplinas de Senge apresentaram aderência com a equipe de tutoria do curso de graduação em Administração a distância da Universidade Federal de Santa Catarina.

As disciplinas domínio pessoal, modelo mental, visão compartilhada, pensamento sistêmico puderem ser claramente identificadas nas respostas dos entrevistados. Cabe salientar que mesmo com a classificação de cada disciplina para as questões, as 5 disciplinas de Senge não são isoladas, podendo corroborar essa afirmação com a análise das entrevistas.

A aprendizagem em equipe teve valores positivos, mas é importante lembrar que é um processo dinâmico e orgânico. Essa aprendizagem está diretamente correlacionada 
com a confiança. A conquista e o fortalecimento da confiança ocorre na rotina e no convívio.

Por fim, ressalta-se que todas as disciplinas de Senge, bem como a confiança, devem ser permeadas por uma sexta disciplina, a ética, essencial para o fortalecimento das variáveis em estudo e para a vida em sociedade.

Cabe ressaltar que a equipe participante da pesquisa convive a sete meses e que neste período algumas transformações ocorreram, pessoas que não se adaptaram, saíram e houve novos entrantes, havia três turnos e foram reduzidos a dois com o objetivo de melhorar a comunicação entre os turnos, ainda com esse mesmo objetivo, o momento da troca de turno tem sido trabalhado com trocas de informações e as lideranças fizeram uma pesquisa e um trabalho com foco na melhoria da comunicação. Essas ressalvas podem fazer a diferença nos resultados encontrados.

\section{REFERÊNCIAS}

BUTLER, J. K. Reciprocity of trust between professionals and their secretaries. Psychological Report, [s.1.], n. 53, p. 411-416, 1983.

CUFAUDE, J. Creating Organizational Trust: Elusive. Fragile. Essential. Association Management, Washington, p. 26-34, July/1999.

FERREIRA, A. B. H. Novo Dicionário da Língua Portuguesa. 2. ed. Rio de Janeiro: Nova Fronteira, 1986.

GOLEMAN, Daniel. Os Mestres da Administração. Rio de Janeiro: Elsevier, 2007.

HASSEGAWA, L. N. O Papel das Interfaces no Sucesso de Projetos Utilizando Equipes Virtuais. São Paulo: USP, 2002. Dissertação (Mestrado em Administração de Empresas) Faculdade de Economia, Administração e Contabilidade, Universidade de São Paulo, 2002.JACOMINO, D. A um clique do MIT. Revista Você S/A, São Paulo, v. 34, n. 4, Abr/2001.

KATZENBACH, J. R.; SMITH, D. K. The Peter F Drucker Foundation for Nonprofit Management's Leader to Leader, n. 22, Fall/2001. In: SCHWEITZER, C. Virtual values. Association Management, Washington, v. 54, n. 3, p. 32-39, Mar/2002.

KELLEY, E. Keys to effective virtual global teams. The Academy of Management Executive, v. 15, n. 2, p. 132-133, May/2001.

LAU, F.; SARKER, S.; SAHAY, S. On Managing Virtual Teams. Mar/1999. Disponível em: <http://www.bus.ualberta.ca/flau/Papers/cacm.htm>

PRENCIPE, L. W. Do you know the rules and manners of an effective virtual meeting? InfoWorld, Framingham, Apr/2001.

NAKAYAMA, M.K., PILLA, B.S. E BINOTTO, E. @-RH conceitos e práticas de RH eletrônico. Porto Alegre: UPF, 2006.

SCHWEITZER, C. Virtual values. Association Management, Washington, v. 54, n. 3, p. 32-39, Mar/2002.

SENGE, Peter. A quinta disciplina: arte e prática da organização que aprende. São Paulo: Best Seller, 1998.

TZAFRIR, S. S.; HAREL, G. H. Confie - em MIM: Uma escala para medir confiabilidade empresário - empregado. Haifa, 2002.

ZAND, D. E. Trust and managerial problem solving. Administrative Science Quarterly, n. 17, p. 229-239, 1972.

ZIMMER, M. V. A Criação de Conhecimento em Equipes Virtuais: Um Estudo de Caso em Empresa do Setor de Alta Tecnologia. Porto Alegre: UFRGS, 2001. Dissertação (Programa de Pós-Graduação em Administração), Escola de Administração, Universidade Federal do Rio Grande do Sul, 2001. 